\title{
Pressure of intraoesophageal varices assessed by fine needle puncture: its relation to endoscopic signs and severity of liver disease in patients with cirrhosis
}

\author{
G KLEBER, T SAUERBRUCH, G FISCHER, AND G PAUMGARTNER \\ From the Department of Medicine II, University of Munich, FRG
}

SUMMARY In 40 patients with cirrhosis and oesophageal varices transmural variceal pressure was assessed endoscopically by fine needle puncture and related to endoscopic signs as well as to the severity of liver disease. Transmural pressure was significantly $(p<0 \cdot 01)$ higher in the presence of a red colour sign $\left(26 \cdot 7(7 \cdot 8) \mathrm{cm} \mathrm{H}_{2} \mathrm{O}\right)$ than in its absence $\left(19 \cdot 1(6 \cdot 6) \mathrm{cm} \mathrm{H}_{2} \mathrm{O}\right)$. Transmural pressure, however, was not significantly related to diameter or number of varices (diameter $>5 \mathrm{mm:} \mathrm{23 \cdot 7}$ $(8 \cdot 4)$, diameter $\leqq 5 \mathrm{~mm}: 22 \cdot 2(7 \cdot 9) \mathrm{cm} \mathrm{H}_{2} \mathrm{O}$; number $>3: 23 \cdot 2(8 \cdot 0)$, number $\left.\leqq 3: 22 \cdot 2(7 \cdot 8) \mathrm{cm} \mathrm{H}_{2} \mathrm{O}\right)$. The Child status (Child A: 23.9 (8.0), Child B/C: $21 \cdot 3(8 \cdot 1) \mathrm{cm} \mathrm{H}_{2} \mathrm{O}$ ) and individual Child-Pugh parameters including ascites (ascites present: $23 \cdot 2(8 \cdot 3) \mathrm{cm} \mathrm{H}_{2} \mathrm{O}$, ascites absent: $22 \cdot 8(8 \cdot 1) \mathrm{cm} \mathrm{H}_{2} \mathrm{O}$ ) were not significantly related to transmural variceal pressure. We conclude that the endoscopic visibility of a red colour sign on the varices is associated with a high transmural oesophageal variceal pressure. Our results favour the hypothesis that variceal pressure may be of major importance for the development of the red colour sign.

Cherry red or haematocystic spots on the variceal surface (red colour sign'), have been supposed to be risk factors for oesophageal variceal haemorrhage in patients with portal hypertension.' It has been suggested that this endoscopic sign corresponds histologically to dilated intraepithelial blood filled channels communicating with subepithelial capillaries. ${ }^{34}$ The pathogenesis of the red colour sign is unknown and its relationship to haemodynamic parameters in patients with cirrhosis has as yet not been evaluated. Only recently, measurement of variceal blood pressure has become a new approach in the evaluation of portal hypertension. ${ }^{56}$ We hypothesised that an increase in blood pressure may be associated with the development of the red colour sign. We therefore measured transmural oesophageal variceal blood pressure in cirrhotic patients with and without the red colour sign on the varices. In addition the relation of transmural oesophageal

Address for correspondence: Dr G Kleber. Department of Medicine II, Klinikum Grosshadern. University of Munich. Marchioninistr. 15, D 80(0) Munich 70, West Germany.

Accepted for publication 11 August 1988 variceal pressure to various other clinical, laboratory and endoscopic parameters was investigated.

\section{Methods}

PATIENTS

Between July 1985 and November 1987 transmural oesophageal variceal pressure was assessed endoscopically immediately before the first sclerotherapy session in 40 patients with liver cirrhosis and medium or large sized (diameter $>2 \mathrm{~mm}$ ) oesophageal varices. Patients characteristics are given in Table 1 .

At the time of pressure measurement various clinical and laboratory parameters were assessed (Table 1). From these the patients were grouped according to a modified Child classification. ' None of the patients were on prophylactic medical treatment for bleeding or on drugs known to reduce variceal or portal blood pressure. All ascitic and 12 of 29 nonascitic patients were on diuretic treatment.

After premedication with $10 \mathrm{mg}$ diazepam and 40 mg n-butylscopolamin an Olympus GIF K 10 endoscope was introduced with the patient in his left 
Table 1 Clinical, laboratory and endoscopic characteristics in cirrhotic patients at the time of assessment of transmural oesophageal variceal blood pressure

\begin{tabular}{lc}
\hline Patients $(\mathrm{n})$ & 40 \\
Age $(\mathrm{yr})$ & $61(10)$ \\
Sex: male/female $(\mathrm{n})$ & $27 / 13$ \\
Aetiology of cirrhosis: alcoholic/non-alcoh. $(\mathrm{n})$ & $22 / 18$ \\
Bleeding history: positive/negative ( $\mathrm{n})$ & $16 / 24$ \\
Severity of liver disease: & \\
Child A/B/C $(\mathrm{n})$ & \\
Bilirubin $(\mu \mathrm{mol} / \mathrm{l})$ & $25 / 11 / 4$ \\
Albumin $(\mathrm{g} / \mathrm{l})$ & $46(62)$ \\
Prothrombin time $(\%)$ & $4 \cdot 0(0 \cdot 6)$ \\
Encephalopathy: present/absent $(\mathrm{n})$ & $73(14)$ \\
Ascites $(\mathrm{n})$ & $13 / 27$ \\
$\quad$ Absent & 29 \\
$\quad$ Moderate & 7 \\
$\quad$ Tense & 4 \\
Endoscopic parameters: & \\
Variceal diameter: $>5 / \leqq 5$ mm (n) & $19 / 21$ \\
Variceal number: $>3 / \leqq 3(\mathrm{n})$ & $27 / 13$ \\
Red colour sign: present/absent $(\mathrm{n})$ & $20 / 20$ \\
Oesophagitis present $(\mathrm{n})$ & 3 \\
\hline
\end{tabular}

lateral position. During endoscopy the diameter (measured with an open biopsy forceps which had a span of $5 \mathrm{~mm}$ ) and number of varices were assessed. In addition, the presence or absence of the red colour

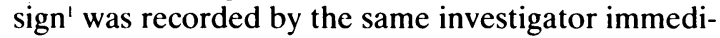
ately before determination of the pressure. The presence of the red colour sign was defined by the visibility of at least one typical red colour sign on the distal part of the varix punctured. In few patients there was only one typical red colour sign visible. The vast majority of the patients, however, exhibited multiple red colour signs on several variceal columns.

Determination of transmural oesophageal variceal pressure was achieved by simultaneous recording of intravariceal and oesophageal luminal pressures. The pressure curves were read by two independent observers who were not involved in assessment of the endoscopic aspect of the varices. For measurement of oesophageal luminal pressure a Teflon tube (od $1.5 \mathrm{~mm}$ ) with an outlet of $0.7 \mathrm{~mm}$ at its tip was attached to the outer surface of the endoscope, with the tip of this tube placed at the end of the endoscope. For measurement of intravariceal pressure a second Teflon tube of the same size, which was connected to a sclerotherapy needle (id $0.4 \mathrm{~mm}$, od $0.6 \mathrm{~mm}$ ), was used. Both tubes were perfused with $0.6 \mathrm{ml} \mathrm{H}_{2} \mathrm{O} /$ min using a high pressure low compliance capillary perfusion system (Mui Scientific, Canada). The tubes were connected to electromechanical transducers and pressures were recorded using a Beckman R 611 dynograph. Calibrations were done before each measurement by rising the needle to varying heights between 0 and $40 \mathrm{~cm} \mathrm{H}_{2} \mathrm{O}$. The sclerotherapy needle was introduced through the biopsy channel of the endoscope and the needle's tip placed outside the endoscope within 1 to $2 \mathrm{~cm}$ from its distal end. After recording of intraoesophageal luminal pressure with both tubes simultaneously (A-B, Fig. 1), the largest variceal column $5 \mathrm{~cm}$ above the gastrooesophageal junction was punctured and the sclerotherapy needle was placed into an intravariceal position in the same way as this is done during routine sclerotherapy. An intramural position of the tip of the needle could be easily detected by an immediate increase of pressure to high values resulting from the tissue resistance to the perfusion (B-C, Fig. 1). The needle then was gently advanced or withdrawn until the tip of the needle was placed in the lumen of the varix. This position was identified by the typical respiration dependent pressure fluctuations (C-D, Fig. 1). With the other tube oesophageal luminal pressure was continuously recorded during measurement of intravariceal pressure. After 30 to 360 seconds of measurement, the sclerotherapy needle was gently withdrawn into the oesophageal
A

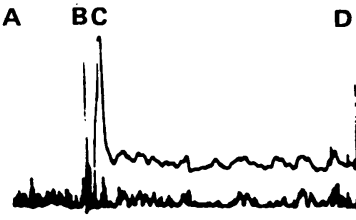

DA

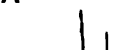

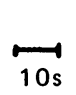$$
\left\lceil 10 \mathrm{~cm} \mathrm{H}_{2} \mathrm{O}\right.
$$

$10 \mathrm{~s}$

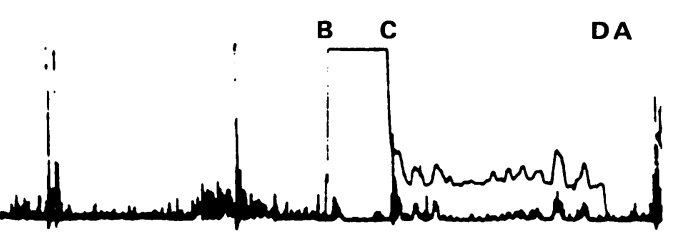

Fig. 1 Simultaneous recording of intravariceal blood pressure and oesophageal luminal pressure. Two measurements were performed consecutively in this patient. Lower line: Continuous oesophageal luminal pressure recording with a tube attached to the outer surface of the endoscope. Upper line: Pressure recording obtained via the sclerotherapy needle: $A-B=$ recording of oesophageal luminal pressure, $B=$ needle punctures variceal wall, the tip of the needle is not yet placed in the variceal lumen, $C-D=$ correct intravariceal position of the needle's tip, which is identified by the typical respiration dependent pressure fluctuations, $D=$ needle is withdrawn from varix. Transmural oesophageal variceal pressure was calculated as the difference between upper and lower line. 
lumen (D, Fig. 1), resulting in a typical oesophageal luminal pressure recording (A-B, Fig. 1). Thereafter, the varix was compressed with the endoscope for three minutes to prevent potential bleeding from the puncture site. No serious complications were observed. We have shown previously that no significant intraindividual pressure changes are observed when repeated measurements are performed before and within 30 minutes after administration of a placebo. ${ }^{9}$ The study was approved by the Ethical Committee of the Faculty of Medicine, University of Munich.

\section{STATISTICAL ANALYSIS}

Results are given as means \pm standard deviation (SD). The relationship between the degree of variceal pressure and the individual clinical, laboratory or endoscopic parameters was performed by the MannWhitney or Fisher's exact test or by linear regression analysis where appropriate.

\section{Results}

In this series of patients with cirrhosis transmural oesophageal variceal pressures ranged from 8.6 to $42 \cdot 5(22 \cdot 9(8 \cdot 1)) \mathrm{cm} \mathrm{H}_{2} \mathrm{O}$.

Transmural pressure was not significantly related to age $(r=-0.05)$, sex (men: $22.4(8.7)$, women: 23.9 $(6 \cdot 7) \mathrm{cm} \mathrm{H}_{2} \mathrm{O}$ ) or etiology of cirrhosis (alcoholic: $22 \cdot 9$ $(8 \cdot 2)$, non-alcoholic: $\left.22 \cdot 9(8 \cdot 1) \mathrm{cm} \mathrm{H}_{2} \mathrm{O}\right)$.

No relationship was found between transmural pressure and diameter or number of varices (Table 2). The transmural pressure was significantly higher, however, in patients in whom the red colour sign was seen on the varices than in the other patients $(26.7$ $(7 \cdot 8) \mathrm{cm} \mathrm{H}_{2} \mathrm{O} v 19 \cdot 1(6.6) \mathrm{cm} \mathrm{H}_{2} \mathrm{O}, \mathrm{p}<0.01$, Table 2, Fig. 2).

The red colour sign was observed significantly $(\mathrm{p}<0.05)$ more frequently in patients in whom the number of varices exceeded three compared with patients with a smaller number of varices. It was not

Table 2 Transmural oesophageal variceal blood pressure $\left(\mathrm{cm} \mathrm{H}_{2} \mathrm{O}\right)$ in relation to endoscopic signs and liver function

\begin{tabular}{|c|c|c|}
\hline \multicolumn{3}{|c|}{ Variceal diameter } \\
\hline$\leqq 5 \mathrm{~mm}$ & $22 \cdot 2(7 \cdot 9)$ & \\
\hline$>5 \mathrm{~mm}$ & $23.7(8.4)$ & $\mathrm{ns}$ \\
\hline \multicolumn{3}{|c|}{ Variceal number } \\
\hline$\leqq 3$ & $22 \cdot 2(7 \cdot 8)$ & \\
\hline$>3$ & $23 \cdot 2(8 \cdot 3)$ & $\mathrm{ns}$ \\
\hline \multicolumn{3}{|c|}{ Red colour sign } \\
\hline Present & $26 \cdot 7(7 \cdot 8)$ & \\
\hline Absent & $19 \cdot 1(6 \cdot 6)$ & $\mathrm{p}<0.01$ \\
\hline \multicolumn{3}{|c|}{ Severity of liver disease } \\
\hline Child A & $23.9(8 \cdot 0)$ & \\
\hline Child B/C & $21 \cdot 3(8 \cdot 1)$ & ns \\
\hline
\end{tabular}

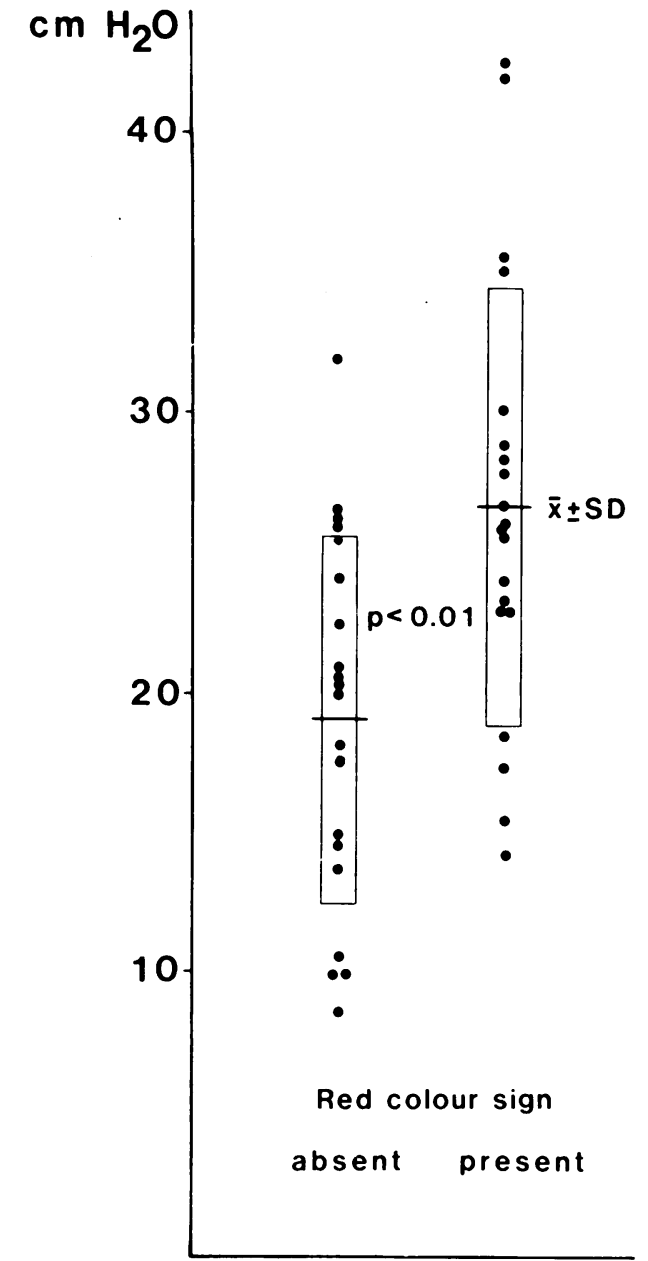

Fig. 2 Transmural oesophageal variceal blood pressure in patients with liver cirrhosis with and without the red colour sign.

related, however, to the variceal diameter (Table 3). None of the endoscopic criteria including the red colour sign (Table 3 ) was significantly related to the clinical or laboratory parameters of the Child-Pugh classification.

Transmural variceal pressure was not significantly related to the Child status (Child A: $23.9(8.0)$, Child $\mathrm{B} / \mathrm{C}: 21.3(8.1) \mathrm{cm} \mathrm{H}_{2} \mathrm{O}$, Table 2) nor to serum bilirubin $(r=-0 \cdot 26)$ or albumin $(r=-0 \cdot 13)$ nor to the prothrombin time $(r=0 \cdot 12)$. No significant association was found between the degree of variceal pressure and the presence of ascites (present: 23.2 (8.3), absent: $\left.22.8(8 \cdot 1) \mathrm{cm} \mathrm{H}_{2} \mathrm{O}\right)$. Transmural variceal pressure was similar in patients treated with diuretics $\left(22.3(7.2) \mathrm{cm} \mathrm{H}_{2} \mathrm{O}\right)$ and in untreated patients $\left(23 \cdot 1(8 \cdot 8) \mathrm{cm} \mathrm{H}_{2} \mathrm{O}\right)$. 
Table 3 Prevalence of the red colour sign in relation to endoscopic signs and liver function

\begin{tabular}{|c|c|c|}
\hline & \multicolumn{2}{|c|}{ Red colour sign } \\
\hline & Present & Absent \\
\hline Patients (n) & 20 & 20 \\
\hline \multicolumn{3}{|l|}{ Oesophagitis } \\
\hline Present & 2 & 1 \\
\hline Absent & 18 & $19 *$ \\
\hline \multicolumn{3}{|c|}{ Variceal diameter } \\
\hline$\leqq 5 \mathrm{~mm}$ & 9 & $12 *$ \\
\hline$>5 \mathrm{~mm}$ & 11 & 8 \\
\hline \multicolumn{3}{|c|}{ Variceal number } \\
\hline$\leqq 3$ & 5 & 11 \\
\hline$>3$ & 15 & $9 \dagger$ \\
\hline \multicolumn{3}{|l|}{ Bilirubin } \\
\hline$<34 \mu \mathrm{mol} / \mathrm{l}$ & 15 & 13 \\
\hline$\geqq 34 \mu \mathrm{mol} / \mathrm{I}$ & 5 & $7 *$ \\
\hline \multicolumn{3}{|l|}{ Albumin } \\
\hline$\leqq 4 \mathrm{~g} / 1$ & 12 & 13 \\
\hline$>4 \mathrm{~g} / 1$ & 8 & $7^{*}$ \\
\hline \multicolumn{3}{|l|}{ Ascites } \\
\hline Present & 4 & 6 \\
\hline Absent & 16 & $14^{*}$ \\
\hline \multicolumn{3}{|l|}{ Child } \\
\hline A & 14 & 11 \\
\hline $\mathrm{B} / \mathrm{C}$ & 6 & $9^{*}$ \\
\hline
\end{tabular}

$*=\mathrm{ns} ; \dagger=\mathrm{p}<0 \cdot 05$.

\section{Discussion}

Improved methods for measurement of intravariceal pressure $^{6}$ have led to renewed interest in this important haemodynamic parameter in patients with oesophageal varices and have made clinical studies feasible. Transmural oesophageal variceal pressures in the present study were obtained by simultaneous recording of intravariceal and oesophageal luminal pressures and were found in a similar range $(8 \cdot 6-42 \cdot 5$ $\mathrm{cm} \mathrm{H}_{2} \mathrm{O}$ ) as those previously reported by others in smaller series. ${ }^{610} \mathrm{We}$ report the relation of this pressure to various endoscopic signs and to the severity of liver disease in 40 patients with cirrhosis. This study group (Table 1) comprised only few Child $C$ patients and did not include patients with very small varices because we feel that exact puncture of these vessels is difficult. Many patients with large varices and no previous bleeding were included because of the relatively large number of patients referred to our endoscopy unit for prophylactic sclerotherapy during the study period.

Evidence has been presented that the red colour $\operatorname{sign}^{1}$ is a bleeding risk indicator in patients with oesophageal varices. ${ }^{2}$ This endoscopic sign corresponds to dilated blood filled channels lying within and beneath the squamous epithelium and communicating with subepithelial capillaries. ${ }^{34}$ Interobserver variability in rating of the presence or absence of the red colour sign has been shown to be low." Thus, the influence on our results by an observation bias is probably minor. Chronic variceal hypertension might cause impairment of variceal tissue structure by "erosion from within' and lead to the development of these lesions. This has been suggested earlier ${ }^{3}$ and is supported by the present study: Transmural oesophageal variceal pressure was nearly $40 \%$ higher in the presence than in the absence of the red colour sign. The finding of a significant correlation between variceal blood pressure and the presence of the red colour sign seemed to be independent from other factors, since neither variceal pressure nor the red colour sign were significantly related to any of the various endoscopic, clinical and laboratory parameters assessed in the present study. The only exception was that the red colour sign was observed in significantly more patients in whom the number of varices exceeded three. This may be the result of the larger variceal surface in these patients. On the other hand, small pressure differences between patient groups with and without the criteria listed in Table 3 may have been missed due to a rather small number of patients in the present study (type II error).

Oesophagitis $^{12}$ - that is, "erosion from without' ${ }^{13}$ has been suggested ${ }^{4}$ to be unlikely to play a major role in the development of the red colour sign and was only occasionally associated with the red colour sign in our patients (Table 1).

Although in contradiction to the results of some, ${ }^{611}$ but not all $^{14}$ authors the absence of a significant correlation between variceal pressure and diameter or number of varices is not a surprise. An increase in portal pressure might well be counterbalanced by a consecutive increase in variceal diameter leading to decreased resistance and increased flow ${ }^{15}$ without a rise in variceal pressure. Small varices, however, were not included in the present study because of the difficulty of pressure measurement. It might well be that these small vessels do have low pressures.

No reports are available on the relationship between variceal pressure and the severity of liver disease. Portal pressure has been found to be slightly higher in patients with severe liver disease as compared with patients with mild liver disease. ${ }^{16}$ We did not find a significant relation between the variceal pressure and the Child status or individual clinical or laboratory tests reflecting the severity of liver disease. This may have been because of the low number of Child $C$ patients included in the study.

It is of particular interest that the presence of ascites was not associated with an increased transmural variceal pressure. Ascites has been suggested $^{1718}$ to be an important indicator of the risk of variceal bleeding. Most authors ${ }^{x_{1-21}}$ have found a rise in portal pressure in ascitic patients. A pre- 
liminary report ${ }^{22}$ suggests that acute experimentally induced intra-abdominal pressure rises cause increments in oesophageal variceal pressure. The effects of chronic portal hypertension on variceal pressure might be different, however: our study shows that transmural oesophageal variceal blood pressure is not higher in patients with ascites than in those without ascites. The results could be interpreted in the sense that a potential increase in portal pressure caused by ascites is counterbalanced by an increased resistance to upper portosystemic collateral flow ${ }^{23}$ or by an increased intrathoracic pressure ${ }^{24}$ as a result of ascites. Both mechanisms would act to reduce transmural variceal pressure either by not allowing portal pressure to be fully transmitted to oesophageal varices or by counterbalancing the intravariceal by a raised extravariceal pressure. It is not clear how portal pressure correlates to variceal pressure because no simultaneous measurements ${ }^{10}$ using the same reference pressure have been reported in the literature.

In conclusion, this study suggests that the red colour sign is an indicator of high variceal pressure. No other endoscopic, clinical or laboratory test including ascites was associated with the degree of variceal pressure rise.

This study was supported by a grant of the WilhelmSander-Foundation, West-Germany. We are indebted to the staff of the endoscopy unit for their help.

\section{References}

1 Japanese Research Society for Portal Hypertension. The general rules for recording endoscopic findings on oesophageal varices. Jpn J Surg 1980; 10: 84-7.

2 Beppu K, Inokuchi K, Koyanagi N, et al. Prediction of variceal haemorrhage by oesophageal endoscopy. Gastrointest Endosc 1981; 27: 213-8.

3 Spence RAJ, Sloan JM, Johnston GW. Histologic factors of the oesophageal transection ring as clues to the pathogenesis of bleeding varices. Surg Gynecol Obstet 1984; 159: 253-9.

4 Spence RAJ, Sloan JM, Johnston GW. Oesophagitis in patients undergoing oesophageal transection for varices - a histological study. Br J Surg 1983; 70: 332-4.

5 Hosking SW, Robinson P, Johnson AG. Usefulness of manometric assessment of varices in maintenance sclerotherapy. A controlled trial. Gastroenterology 1987; 93: 846-51.

6 Staritz M, Poralla T, Meyer zum Büschenfelde K-H. Intravascular oesophageal variceal pressure (IOVP) assessed by endoscopic fine needle puncture under basal conditions, Valsalva's manoeuvre and after glyceryltrinitrate application. Gut 1985; 26: 525-30.
7 Pugh RNH, Murray-Lyon IM, Dawson JL. Transsection of the oesophagus for bleeding oesophageal varices. Br J Surg 1973; 60: 646-9.

8 Ginés P. Arroyo V, Quintero E. Comparison of paracentesis and diuretics in the treatment of cirrhotics with tense ascites. Gastroenterology 1987; 93: $234-41$.

9 Kleber G, Sauerbruch T, Fischer G, Paumgartner G. Somatostatin does not reduce oesophageal variceal pressure in liver cirrhotics. Gut 1988; 29: 153-6.

10 Rigau J, Bosch J, Bordas JM, et al. Variceal Pressure. measured at endoscopy, but not portal pressure correlates with the risk of bleeding from oesophageal varices in cirrhosis [Abstract]. J Hepatol 1984; 2: 238.

11 The Italian Liver Cirrhosis Project. Reliability of endoscopy in the assessment of variceal features. $J$ Hepatol 1987; 4: 93-8.

12 Cheli R, Simon L, Elster K, Bocchini R. Ocsophagitis in Italian and Hungarian asymptomatic subjects. Endoscopy 1982; 14: 1-3.

13 Liebowitz HR. Pathogenesis of oesophageal varix rupture. JAMA 1961; 175: 138-43.

14 Palmer ED, Brick IB. Correlation between the severity of oesophageal varices and their propensity towards haemorrhage. Gastroenterology 1956; 30: 85-90.

15 Bosch J, Groszman RJ. Measurement of azygos venous blood flow through gastrooesophageal collaterals in cirrhosis. Hepatology 1984; 4: 424-9.

16 Braillon A, Cales P, Valla D, Gaudy D, Geoffroy P, Lebrec D. Influence of the degree of liver failure on systemic and splanchnic haemodynamics and on response to propranolol in patients with cirrhosis. Gut 1986; 27: 1204-9.

17 Conn HO, Lindenmuth WW, May CJ, Ramsby GR. Prophylactic portacaval anastomosis. A tale of two studies. Medicine 1972; 51: 27-40.

18 Resnick RH, Chalmers TC, Ishihara AM, et al. Boston Inter-Hospital Liver Group. A controlled study of the prophylactic portacaval shunt. A final report. Ann Intern Med 1969; 70: 657-88.

19 Reynolds TB, Redeker AG, Geller AM. Wedged hepatic venous pressure. Am J Med 1957; 22: 341-50.

20 Smith-Laing G, Camillo ME, Dick R, Sherlock S. Percutaneous transhepatic portography in the assessment of portal hypertension. Clinical correlations and comparison of radiographic techniques. Gastroenterology 1980; 78: 197-205.

21 Vinel JP, Chassigneul J, Louis A. Clinical and prognostic significance of portohepatic gradients in patients with cirrhosis. Surg Gynecol Obstet 1982; 144: 347-52.

22 Westaby D, Gimson A, Williams R. Oesophageal varix pressure measurement: the relations to portal pressure and the responses to changes in intraabdominal pressure [Abstract]. Gut 1985; 26: A562.

23 Iwatsuki S, Reynolds TB. Effect of increased intraabdominal pressure on hepatic hemodynamics in patients with chronic liver disease and portal hypertension. Gastroenterology 1973; 65: 294-9.

24 Kashtan J, Green JF, Parsons EQ, Holcroft JW. Hemodynamic effects of increased abdominal pressure. J Surg Res 1981; 30: 249-55. 